\title{
Titrated extract of Centella asiatica provides a UVB protective effect by altering microRNA expression profiles in human dermal fibroblasts
}

\author{
IN-SOOK AN $^{1 *}$, SUNGKWAN AN ${ }^{1,2^{*}}$, SANG-MO KANG ${ }^{3}$, TAE-BOO CHOE $^{3}$, \\ SUNG NAE LEE ${ }^{4}$, HYUN HEE JANG ${ }^{5}$ and SEUNGHEE BAE ${ }^{2}$
}

\author{
${ }^{1}$ Korea Institute for Skin and Clinical Sciences, ${ }^{2}$ Molecular-Targeted Drug Research Center, \\ and ${ }^{3}$ Department of Microbial Engineering, Konkuk University, Seoul 143-701; ${ }^{4}$ Department of Cosmetology, \\ Kyung-In Women's College, Incheon Metropolitan City 407-740; ${ }^{5}$ School of Cosmetology, \\ Kyungbok University, Pocheon-si, Gyeonggi-do 487-717, Republic of Korea
}

Received June 5, 2012; Accepted August 20, 2012

DOI: $10.3892 / \mathrm{ijmm} .2012 .1117$

\begin{abstract}
The titrated extract of Centella asiatica (TECA) is a reconstituted mixture comprising of asiatic acid, madecassic acid, asiaticoside and madecassoside, and is used as a therapeutic agent in wound healing and also as an anti-microbial, anticancer and anti-aging agent. Although these properties and the associated cell signaling pathways have been elucidated, the cellular mechanism of anti-photoaging upon ultraviolet (UV) exposure in normal human dermal fibroblasts (NHDFs) remains unknown. In this study, we investigated the photoprotective role of TECA via microRNA (miRNA) expression profiling analysis. Low dose of TECA did not exhibit toxicity and showed a protective effect against UVB irradiation in NDHFs. miRNA microarray experiments revealed that specific miRNAs were altered by TECA stimulation in UVB-irradiated NHDFs. Functional bioinformatic analysis showed that the putative target genes of the altered miRNAs were associated with the positive regulation of cell proliferation, anti-apoptosis, small GTPase- and Ras-mediated signal transduction and activation of MAPKK. Therefore, these results suggest that TECA may serve as a potential natural chemoprotective agent against UVB-mediated damage in NHDFs through changes in the expression of specific miRNAs.
\end{abstract}

\section{Introduction}

Centella asiatica (L.) Urb. (Apiaceae), also known as pegaga and gotu kola, has been used as a medicine in tropical regions.

Correspondence to: Dr Seunghee Bae, Molecular-Targeted Drug Research Center, Konkuk University, 1 Hwayangdong, Gwangjin-gu, Seoul 143-701, Republic of Korea

E-mail: sbae@konkuk.ac.kr

${ }^{*}$ Contributed equally

Key words: Centella asiatica, dermal fibroblast, UVB irradiation, miRNA expression, cell viability
This plant contains pharmacologically active compounds including various pentacyclic triterpene derivatives, such as centelloids (1-3). The Centella asiatica ( $C$. asiatica) extract contains four major triterpenoids, namely asiatic acid, madecassic acid, asiaticoside and madecassoside, and this mixture is commercially marketed as a titrated extract of Centella asiatica (TECA). The $C$. asiatica extract is used as an anti-microbial, anti-oxidative and anticancer agent, as well as a therapeutic agent in the various processes of wound healing, such as coagulation, inflammation, cell migration and proliferation as well as scar formation and remodeling (4-9). Following reports of the wound-healing properties of C. asiatica in various studies, it has been used in skin cell development and therapy. The major components of the skin are collagen types I and III, which play a key role in wound healing and are directly related to skin aging (10). Indeed, the C. asiatica extract can promote an increase in both fibronectin and collagen synthesis by $20-35 \%$ in skin fibroblasts $(7,10-12)$. Furthermore, the $C$. asiatica extract plays an important role in the process of anti-oxidation by reducing the activity of reactive oxygen species (ROS), and thus prevents hydrogen peroxide $\left(\mathrm{H}_{2} \mathrm{O}_{2}\right)$-induced senescence in normal human dermal fibroblasts (NHDFs) (13-15).

Similar to ROS, ultraviolet (UV) radiation targets the skin and continues to induce skin aging and cancer. Among the three types of UV light (UVA, UVB and UVC), the UVB light only penetrates into the epidermis and, therefore, UVB radiation at a high dose can elicit severe skin damage. UV radiation stimulates several biological processes in the skin, which include adaptive, inflammatory and immunological reactions. Following UV irradiation, adaptive responses are induced in the form of stratum corneum thickening, pigmentation and epidermal hyperplasia $(16,17)$. UV exposure mediates an inflammatory response, which is manifested as erythema and redness, and is followed by the induction of apoptosis in keratinocytes $(16,18)$. Therefore, chronic UV irradiation results in skin photoaging, which is characterized by irregular pigmentation, dryness of the skin, wrinkling and elastosis $(18,19)$. Also, UV radiation activates multiple signaling cascades, 
such as p38 mitogen-activated protein kinase (MAPK), Jun $\mathrm{N}$-terminal kinase (JNK), extracellular signal-regulated kinase $1 / 2$ (ERK1/2) and the NFKB pathways in skin cells (19).

A preliminary study suggested that the $C$. asiatica extract can serve as a potential natural protectant against UVB damage in NHDFs (20). However, the cellular mechanisms underlying the photoprotective effect of TECA against UV irradiation have yet to be studied. This is the first report to elucidate the cellular mechanisms of TECA-mediated photoprotection against UV through the investigation of microRNA (miRNA) expression profiling changes in NHDFs.

\section{Materials and methods}

Cell culture. The NHDF cells were purchased from Lonza (Basel, Switzerland) and grown in DMEM media (GibcoInvitrogen Life Technologies, Carlsbad, CA, USA) containing $10 \%$ fetal bovine serum (FBS; Sigma-Aldrich, St. Louis, MO, USA) with penicillin/streptomycin in a humidified chamber at $37^{\circ} \mathrm{C}$ under $5 \% \mathrm{CO}_{2}$. Cells $\left(4 \times 10^{3}\right)$ were seeded into 96 -well plates a day before UVB exposure and treatment with the C. asiatica extract. For RNA purification, $7 \times 10^{5}$ cells were seeded into $60-\mathrm{mm}$ dishes.

UVB irradiation and TECA treatment. Prior to UVB irradiation, cells were pre-treated with control dimethylsulfoxide (DMSO; Sigma-Aldrich) or TECA (Bayer HealthCare, Berlin, Germany) for $4 \mathrm{~h}$. Cells were washed with PBS twice and then exposed to $100 \mathrm{~mJ} / \mathrm{cm}^{2} \mathrm{UVB}$ without covering the 96 -well plates or $60-\mathrm{mm}$ dishes, so that the UVB light was not filtered. Following irradiation, the cells were cultured for $24 \mathrm{~h}$ in DMEM media containing 10\% FBS with DMSO or TECA.

RNA purification and qualification. NHDF cells exposed to UVB with or without TECA were collected, and then total-RNA, including mRNAs, small RNAs and miRNAs, was extracted and purified from each cell pellet using TRIzol reagent (Invitrogen Life Technologies) according to the manufacturer's protocol. The integrity of each RNA sample was verified using an Agilent 2100 Bioanalyzer $^{\circledR}$ (Agilent Technologies, Santa Clara, CA, USA). The quality and concentration of each RNA sample were determined using MaestroNano ${ }^{\circledR}$, a micro-volume spectrophotometer (Maestrogen, Las Vegas, NV, USA). RNA quality parameters for the miRNA microarray analysis were: A260/280 and A260/ A230 values $>1.8$ and an RNA integrity number $(\mathrm{RIN})>8.0$.

Microarray analysis of miRNA expression. The miRNA profiling analysis was performed using the SurePrint G3 Human v16 miRNA 8x60K (Agilent Technologies) that contained probes for 1,205 and 144 human viral miRNAs. The qualified RNA samples (100 ng) were first dephosphorylated using calf intestinal alkaline phosphatase (CIP) at $37^{\circ} \mathrm{C}$ for $30 \mathrm{~min}$. Next, DMSO was added to each sample, and the samples were incubated at $100^{\circ} \mathrm{C}$ for $10 \mathrm{~min}$ and immediately transferred to an ice-water bath. The dephosphorylated RNA samples were labeled with cyanine 3-pCp using T4 RNA ligase by incubation at $16^{\circ} \mathrm{C}$ for $2 \mathrm{~h}$. After the labeling reaction, the samples were completely dried using a vacuum concentrator at $55^{\circ} \mathrm{C}$ for $4 \mathrm{~h}$. The dried samples were treated with GE Blocking Agent (Agilent Technologies) and hybridized to the probes on the microarray at $55^{\circ} \mathrm{C}$ with a constant rotation at $20 \mathrm{rpm}$ in the Agilent Microarray Hybridization Chamber (Agilent Technologies) for $20 \mathrm{~h}$. The microarray slide was washed and scanned using the Agilent scanner to obtain the microarray image. The numerical data for the miRNA profiles were extracted from the image using the Feature Extraction program (Agilent Technologies). These data were analyzed with the aid of the GeneSpring GX software version 7.3 (Agilent Technologies).

Classification of miRNAs. Among the total miRNAs probed on the microarray, 866 human miRNAs were selected for further analysis. The miRNAs whose flags were present in at least one sample were filtered and applied to the fold-change analysis. The fold-change analysis was conducted to select miRNAs whose expression changed by a factor of 1.2-fold or more between the following two groups: UVB-exposed and DMSO-treated NHDF control cells and UVB-exposed and $50 \mu \mathrm{g} / \mathrm{ml}$ TECA-treated NHDFs.

Bioinformatic analysis of miRNAs. Changes in miRNA expression of 1.2-fold and more between the two groups were selected, and their putative cellular target genes were determined using MicroCosm Target version 5 (www.ebi.ac.uk/enrightsrv/microcosm/thdoc/targets/v5/). Using a gene ontology (GO) analysis tool, AmiGO (amigo.geneontology.org/cgi-bin/ amigo/browse.cgi), the target genes were categorized into the following four groups: aging, apoptosis, cell proliferation and skin development. Further GO analysis for miRNA target genes that were also identified by cross-linking and Argonaute (Ago) immunoprecipitation coupled with high-throughput sequencing (CLIP-Seq) data was performed using starBase web-based bioinformatics tools (starBase.sysu.edu.cn) (21).

\section{Results}

TECA treatment inhibits the decrease in cell viability caused by UVB irradiation in NHDFs. We first screened for the dose range of TECA that is cytotoxic to NHDF cells. NHDF cells were treated with a series of four concentrations of TECA $(25,50,100$ and $200 \mu \mathrm{g} / \mathrm{ml})$ for $24 \mathrm{~h}$, and the WST-1-based cellular toxicity assay was used to determine the level of cell viability. As shown in Fig. 1A, low doses (up to $50 \mu \mathrm{g} / \mathrm{ml}$ ) of TECA increased cell viability slightly; however, relatively high doses (100 and $200 \mu \mathrm{g} / \mathrm{ml})$ of TECA decreased cell viability. In particular, although $100 \mu \mathrm{g} / \mathrm{ml}$ of TECA exhibited a low toxicity on NHDF cells, $200 \mu \mathrm{g} / \mathrm{ml}$ of TECA largely decreased cell viability. Therefore, TECA concentrations of 25,50 and $100 \mu \mathrm{g} / \mathrm{ml}$ were chosen for further experiments. Next, we investigated the protective effect of TECA treatment against UVB-mediated damage of NHDFs. A day before UVB irradiation, NHDF cells were seeded and incubated in 96-well plates. The cells were then pre-treated with TECA, at the indicated concentration, for $4 \mathrm{~h}$. The cells were then washed with PBS and exposed to $100 \mathrm{~mJ} / \mathrm{cm}^{2}$ of UVB without putting any protective covers on the microplates. Following UVB irradiation, the cells were incubated with TECA, at the indicated concentration, for $24 \mathrm{~h}$. Cell viability was determined using the WST-1 assay, which revealed 


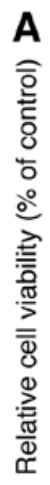
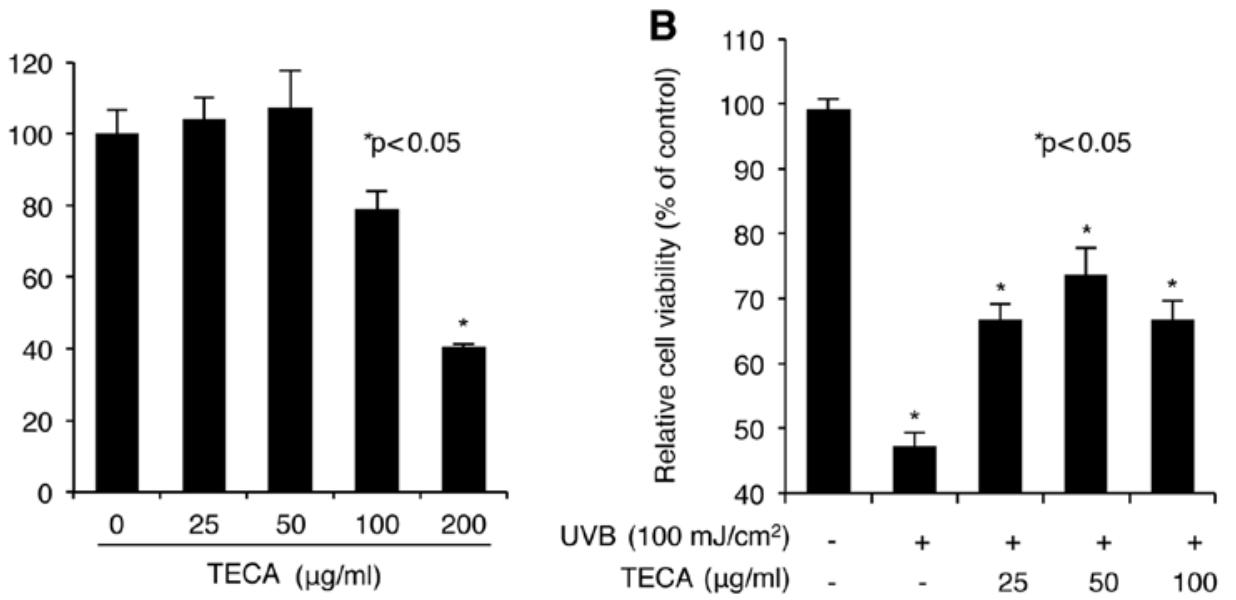

Figure 1. UVB-mediated loss of cell viability in NHDFs was recovered by TECA treatment. (A) The cellular toxicity of TECA on NHDF cells. NHDF cells $\left(4 \times 10^{3}\right.$ cells) were seeded on 96-well plates and then treated with a series of indicated TECA concentrations for 24 h. Cellular toxicity was measured by the WST-1 assay. The graph represents the mean \pm SD of the relative cell viability in each sample from triplicate experiments. The Student's t-test was performed to determine statistical significance $(* \mathrm{p}<0.05)$. (B) The protective effect of TECA treatment against UVB-induced damage in NHDF cells. After seeding NHDF cells $\left(4 \times 10^{3}\right.$ cells) on 96 -well plates, the cells were incubated for $24 \mathrm{~h}$. Prior to UVB exposure, the cells were pre-treated with control DMSO and TECA for $4 \mathrm{~h}$. Then, the cells were washed with PBS and exposed to $100 \mathrm{~mJ} / \mathrm{cm}^{2}$ of UVB radiation without filter protection. After exposure, the cells were incubated with media containing DMSO and various concentrations of TECA as indicated. After further incubation for $24 \mathrm{~h}$, cell viability was determined using the WST-1 assay. The results are representative of three independent experiments (mean \pm SD are shown). The Student's t-test was performed to determine statistical significance $(* \mathrm{p}<0.05)$.

A

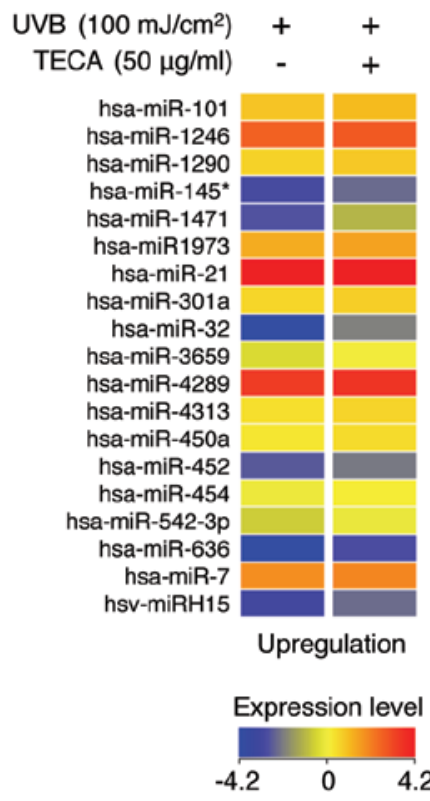

B

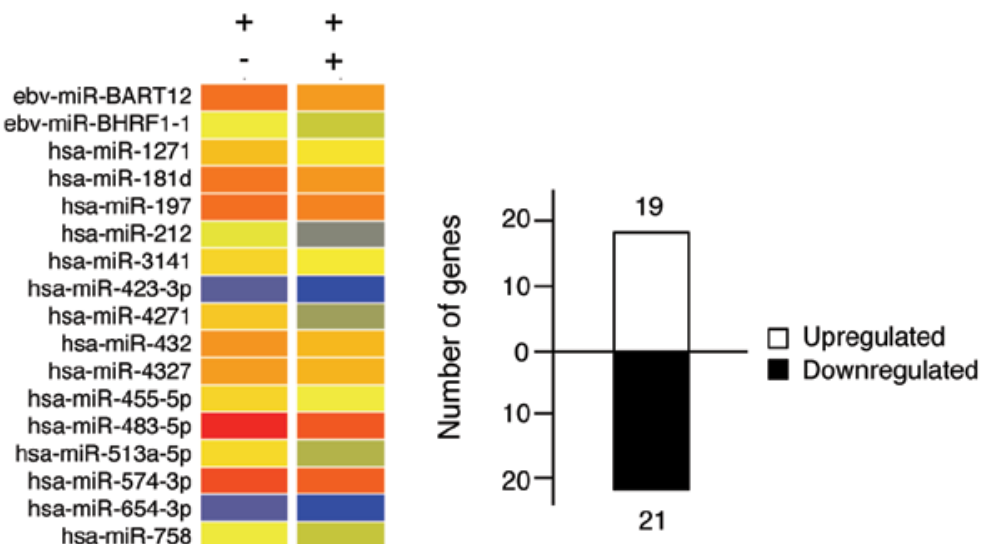

hsa-miR-765

hsa-miR-887

hsv1-miR-H1* kshv-miR-K12-10b

Downregulation
(1)

Figure 2. Change in miRNA expression due to TECA treatment. (A) TECA treatment of UVB-exposed NHDF cells induces changes in miRNA expression profiles. NHDFs were pre-treated with TECA $(50 \mu \mathrm{g} / \mathrm{ml})$ for $4 \mathrm{~h}$ and washed with PBS. The cells were then exposed to UVB irradiation and further incubated with fresh media containing DMSO or TECA. The cells were collected and total-RNA of each sample was purified. miRNA microarrays were performed to identify the changes in miRNA expression profiles. The types of miRNAs upregulated (left panel) and downregulated (right panel) by TECA treatment and their expression levels in UVB-exposed NHDF cells are represented by a heat-map image. (B) The graph represents the number of upregulated and miRNA downregulated by TECA treatment of UVB-exposed NHDF cells. Asterisk (") represents passenger strand from the miRNA duplex.

that treatment with TECA, in the range of 25 and $50 \mu \mathrm{g} / \mathrm{ml}$, markedly restored the UVB-mediated loss of cell viability in NHDFs to the normal status in a dose-dependent manner (Fig. 2B). Treatment with $100 \mu \mathrm{g} / \mathrm{ml}$ of TECA did not increase cell viability more than the $50 \mu \mathrm{g} / \mathrm{ml}$ of TECA, which can be attributed to the cytotoxic effect of $100 \mu \mathrm{g} / \mathrm{ml}$ TECA on NHDF cells. Therefore, TECA displayed a protective effect against UVB-mediated loss of cell survival observed in NHDF cells.

The protective role of TECA in UVB-induced NHDF damage is reflected as miRNA expression profiling changes. Since miRNA is an important small non-coding RNA molecule that regulates development, differentiation, proliferation and 
Table I. miRNAs altered by TECA in UVB-exposed NHDF cells.

\begin{tabular}{|c|c|c|c|c|c|}
\hline \multicolumn{3}{|c|}{ Upregulated } & \multicolumn{3}{|c|}{ Downregulated } \\
\hline miR name & $\mathrm{FC}$ & Chromosome & miR name & $\mathrm{FC}$ & Chromosome \\
\hline hsa-miR-101 & 1.24 & Chr1 & ebv-miR-BART12 & 1.47 & - \\
\hline hsa-miR-1246 & 1.21 & Chr2 & ebv-miR-BHRF1-1 & 1.24 & - \\
\hline hsa-miR-1290 & 1.20 & Chr1 & hsa-miR-1271 & 1.39 & Chr5 \\
\hline hsa-miR-145* & 1.27 & Chr5 & hsa-miR-181d & 1.34 & Chr19 \\
\hline hsa-miR-1471 & 2.08 & Chr2 & hsa-miR-197 & 1.20 & Chr1 \\
\hline hsa-miR-1973 & 1.25 & Chr4 & hsa-miR-212 & 1.67 & Chr17 \\
\hline hsa-miR-21 & 1.21 & Chr17 & hsa-miR-3141 & 1.21 & Chr5 \\
\hline hsa-miR-301a & 1.21 & Chr17 & hsa-miR-423-3p & 2.01 & Chr17 \\
\hline hsa-miR-32 & 2.65 & Chr9 & hsa-miR-4271 & 2.38 & Chr3 \\
\hline hsa-miR-3659 & 1.28 & Chr1 & hsa-miR-432 & 1.35 & Chr14 \\
\hline hsa-miR-4286 & 1.24 & Chr8 & hsa-miR-4327 & 1.22 & Chr21 \\
\hline hsa-miR-4313 & 1.27 & Chr15 & hsa-miR-455-5p & 1.35 & Chr9 \\
\hline hsa-miR-450a & 1.29 & ChrX & hsa-miR-483-5p & 1.71 & Chr11 \\
\hline hsa-miR-452 & 1.23 & ChrX & hsa-miR-513a-5p & 1.81 & ChrX \\
\hline hsa-miR-454 & 1.29 & Chr17 & hsa-miR-574-3p & 1.20 & Chr4 \\
\hline hsa-miR-542-3p & 1.25 & ChrX & hsa-miR-654-5p & 1.79 & Chr14 \\
\hline hsa-miR-636 & 1.83 & Chr17 & hsa-miR-758 & 1.25 & Chr14 \\
\hline hsa-miR-7 & 1.20 & Chr9 & hsa-miR-765 & 1.75 & Chr1 \\
\hline \multirow[t]{3}{*}{ hsv1-miR-H15 } & 1.39 & - & hsa-miR-887 & 1.24 & Chgr5 \\
\hline & & & hsv1-miR-H1* & 2.35 & - \\
\hline & & & kshv-miR-K12-10b & 1.51 & - \\
\hline
\end{tabular}

The list was selected to show miRNAs representing $>1.2$-fold change in expression after flag sorting. "Non-functional miRNA or passenger strand that is released from the miRNA duplex.

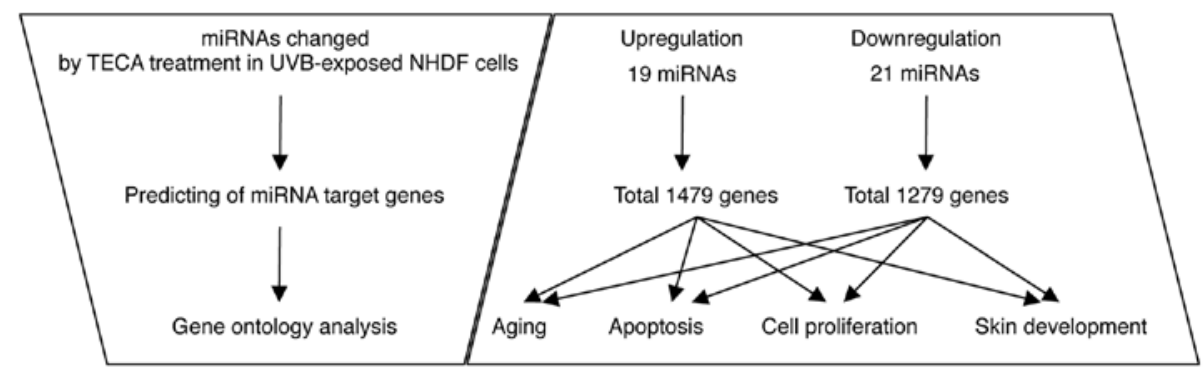

Figure 3. Bioinformatic analysis pipeline in this study. After selecting the differentially expressed miRNAs following TECA treatment of UVB-exposed NHDF cells, the cellular functions of the selected miRNAs were determined by several bioinformatic tools, such as MicroCosm, AmiGO and starBase. The putative cellular target genes of each miRNA were predicted by MicroCosm. The target genes were categorized into four groups, based on their functions related to aging, apoptosis, cell proliferation and skin development. Further GO analysis of the miRNA target genes was performed using the starBase database.

apoptosis (22-25), we determined the protective effect of TECA against UVB-induced cell damage through a miRNA expression profiling analysis. Total-RNAs were purified from UVB-irradiated NHDF control cells and from $50 \mu \mathrm{g} / \mathrm{ml}$ of TECA-stimulated and UVB-irradiated NHDF cells, after which miRNA microarrays were performed using the Agilent SurePrint G3 Human v16 miRNA 8x60K, as described in Materials and methods. A total of 1,205 human miRNAs, including 144 human viral miRNAs, were selected to analyze the miRNA profiles. The human miRNAs whose flags were present in at least one sample were continuously filtered to obtain more defined data using the Agilent GeneSpring software. As shown in Fig. 2A, a total of 40 human miRNAs were differentially expressed following stimulation with TECA in UVB-irradiated NHDF cells compared to cells exposed to UVB alone. Upregulated miRNAs are shown in the left panel and downregulated miRNAs are shown in the right panel of Fig. 2A. The color bar displaying altered fluorescence intensity corresponds to miRNAs that were either upregulated (red colors) or downregulated (blue color) by TECA stimulation. The full list of the 40 miRNAs whose expression was altered by TECA is listed in Table I. The 
Table II. Predicted targets of miRNAs exhibiting an upregulation in response to TECA in UVB-exposed NHDF cells.

\begin{tabular}{|c|c|c|c|c|}
\hline \multirow[b]{2}{*}{ miRNA name } & \multicolumn{4}{|c|}{ Function of target genes } \\
\hline & Aging & Apoptosis & Cell proliferation & $\begin{array}{l}\text { Skin } \\
\text { development }\end{array}$ \\
\hline hsa-miR-21 & $\begin{array}{l}\text { TBX2, PTEN, } \\
\text { LRP2, MSH2, } \\
\text { PDCD4 }\end{array}$ & $\begin{array}{l}\text { ARHGEF12, BCL7, CCR7, } \\
\text { FASLG, KRIT1, LRP2, } \\
\text { MAP3K1, NTF3, PDCD4, } \\
\text { PTEN, RHOB, SKI, TIAM1, } \\
\text { UBE2D3, SATB1, ACVR1C }\end{array}$ & $\begin{array}{l}\text { DDX11, FGF1, GATAD2B, } \\
\text { IL12A, JAG1, KRIT1, LRP6, } \\
\text { PBRM1, PELI1, PITX2, SKI, } \\
\text { SPRY1, TBX2, TGFB1 }\end{array}$ & - \\
\hline hsa-miR-32 & $\begin{array}{l}\text { HCN2, NOX4, } \\
\text { PER2, TWIST1, } \\
\text { ADRB1 }\end{array}$ & $\begin{array}{l}\text { ACTC1, ARHGEF17, BCL2L11, } \\
\text { BTG2, GATA6, HAND2, HIPK3, } \\
\text { ITGA6, ITGAV, KIF1B, LYST, } \\
\text { MAP2K4, RAD21, SGK3, } \\
\text { TRAF3, TRIO, TWIST1, } \\
\text { UBE2Z, ADRB1, CDK5R1, GP1, } \\
\text { JMY, NR4A3, SNF1LK }\end{array}$ & $\begin{array}{l}\text { BTG2, CDC27, CDCA7L, } \\
\text { CDKN1C, FOSL2, GATA2, } \\
\text { MS4A2, NKX2-3, NOX4, } \\
\text { PAX3, PCAF, PTPRK, } \\
\text { TACC2, TGIF1, TOB2, } \\
\text { RAP1B, SOX11, BMPR2, } \\
\text { TSC1, ZEB2 }\end{array}$ & $\begin{array}{l}\text { BCL11B, } \\
\text { COL1A2 }\end{array}$ \\
\hline hsa-miR-101 & $\begin{array}{l}\text { FOS, TIAM2, } \\
\text { ADRB1, LRP2 }\end{array}$ & $\begin{array}{l}\text { ARHGEF3, DUSP1, JAK2, } \\
\text { MSX1, PHLDA1, PROK2, } \\
\text { RAC1, SCN2A, SGK1, TGFBR1, } \\
\text { USP47, UBE2D3, ADRB1, } \\
\text { CDKR1, GPI, DDIT4, MITF, } \\
\text { PRKCE, TCF7L2, ROBO2, } \\
\text { GJA1, NEUROD1, PRKAA1, }\end{array}$ & $\begin{array}{l}\text { CDH5, CEBPA, DLG5, } \\
\text { ELF5, EMP1, GNB1, HRB, } \\
\text { JAK2, NDFIP1, PDS5B, } \\
\text { PTGS2, RXRB, SOX9, } \\
\text { TAL1, TGFA, TGFBR1, } \\
\text { UBE2A, RAP1B, SOX11, } \\
\text { FZD6, LRP2, PTCH1 }\end{array}$ & - \\
\hline hsa-miR-7 & - & $\begin{array}{l}\text { AMBRA1, COL2A1, CTSB, } \\
\text { FNDC4, GLI3, HELLS, OGT, } \\
\text { PRMT2, PSME3, RAF1, RB1, } \\
\text { SNCA, SORT1, VDAC1, SATB1, } \\
\text { DDIT4, JMY, NR4A3, PHF17 }\end{array}$ & $\begin{array}{l}\text { CONT8, CUL5, EGFR, } \\
\text { IRS1, PAX6, UHRF1, } \\
\text { SATB1, IRS2 }\end{array}$ & COL2A1 \\
\hline hsa-miR-301a & $\begin{array}{l}\text { TP63, WNT1, } \\
\text { LRRK2, LRP2 }\end{array}$ & $\begin{array}{l}\text { DLC1, TP63, WNT1, TP63, } \\
\text { APPL1, FXR1, SOX4, ROBO2 }\end{array}$ & $\begin{array}{l}\text { DLEC1, ESR1, BMPR2, TSC1, } \\
\text { USP28, ZEB2, EREG, FOSL1, } \\
\text { HOXA3, IMPDH1, INSIG1, IRF1, } \\
\text { JARID2, LRRK2, NR3C2, } \\
\text { PPARG, TBC1D8, WNT28, } \\
\text { FZD6, LRP2 }\end{array}$ & $\begin{array}{l}\text { TP63, } \\
\text { WNT10A, } \\
\text { EDA }\end{array}$ \\
\hline hsa-miR-452 & $\begin{array}{l}\text { IGF2BP2, } \\
\text { TIMP3 }\end{array}$ & ERBB4, VEGFA, IGF1 & $\begin{array}{l}\text { BMI1, CDKN1B, EPS8, } \\
\text { ERBB4, IGF2BP2, } \\
\text { LAMC1, MAB21L2, } \\
\text { MAPRE1, MXD1, NPPC, } \\
\text { PURA, RPA1, TIMP2, } \\
\text { VEGFA, PTPRJ, IRS2 }\end{array}$ & - \\
\hline hsa-miR-636 & SOCS3 & $\begin{array}{l}\text { ARF6, GRIK2, ITSN1, PCGF2, } \\
\text { PKN2, PROC, RPS6KA2, RTN3, } \\
\text { SENP1, SFRP2, SOCS3, MITF, } \\
\text { PRKCE, TCF7L2, SNF1LK, } \\
\text { TGFBR2, ZAK }\end{array}$ & $\begin{array}{l}\text { BCAT1, EMX2, LIFR, SSR1, } \\
\text { TRAF5, MITF, TOB1 }\end{array}$ & - \\
\hline hsa-miR-454 & LRRK2, LRP2 & $\begin{array}{l}\text { NELL1, APPL1, FXR1, SOX4, } \\
\text { ROBO2, SIX4, ARHGEF4, } \\
\text { BTG1, PAK6, POU4F1, } \\
\text { PRKAA2, RASA1, RNF216, } \\
\text { RNF41, RNUX3, SLTM, SOS2, } \\
\text { SPHK2, TP53INP1, TRIM2, } \\
\text { GJA1, NEUROD1, PRKAA1, } \\
\text { SYNGAP1, IGF1, ZAK }\end{array}$ & $\begin{array}{l}\text { NRP1, TNF, BMPR2, } \\
\text { TSC1, USP28, ZEB2, } \\
\text { BTG1, EREG, FOSL1, } \\
\text { HOXA3, IMPDH1, } \\
\text { INSIG1, IRF1, JARID2, } \\
\text { LRRK2, NR3C2, PPARG, } \\
\text { RUNX3, TBC1D8, } \\
\text { WNT2B, FZD6, LRP2 }\end{array}$ & EDA \\
\hline
\end{tabular}


Table III. Predicted targets of miRNAs exhibiting a downregulation in response to TECA in UVB-exposed NHDF cells.

\begin{tabular}{|c|c|c|c|c|}
\hline \multirow[b]{2}{*}{ miRNA name } & \multicolumn{4}{|c|}{ Function of target genes } \\
\hline & Aging & Apoptosis & Cell proliferation & $\begin{array}{c}\text { Skin } \\
\text { development }\end{array}$ \\
\hline hsa-miR-197 & - & $\begin{array}{l}\text { CECR2, CTNNA1, CYLD, } \\
\text { TNFRSF21, RASA1, } \\
\text { HIPK2, GP1 }\end{array}$ & $\begin{array}{l}\text { FZD3, IGFBP3, TAL1, } \\
\text { FBXW7, HIPK2, PDGFRA }\end{array}$ & - \\
\hline hsa-miR-212 & CTGF & $\begin{array}{l}\text { ARHGEF11, CTGF, DYRK2, } \\
\text { EP300, FOXA1, FOXO3, GDF5, } \\
\text { ISL1, KCNMA1, MAPK3, } \\
\text { MAPT, RASA1, SGK3, RASA1 }\end{array}$ & $\begin{array}{l}\text { CTGF, EGR1, HHIP, ISL1, } \\
\text { RB1, SALL1, SPRY1, } \\
\text { ZEB2, HBEGF, SOX11 }\end{array}$ & - \\
\hline hsa-miR-432 & DLD, MNT & $\begin{array}{l}\text { ADAR, CHAC1, DAB2IP, } \\
\text { HOXA5, IL7, MNT, PAX8, } \\
\text { PLK3, SORT1, HIPK2 }\end{array}$ & $\begin{array}{l}\text { CCDC88A, E2F3, IL7, } \\
\text { MNT, FBXW7, HIPK2 }\end{array}$ & - \\
\hline hsa-miR-181d & $\begin{array}{l}\text { ADRBK1, PRKCD, } \\
\text { PAI, SIRT1, TIMP3 }\end{array}$ & $\begin{array}{l}\text { ANKRD13C, ATM, BAG4, } \\
\text { BCL2L11, BIRC6, CARD11, } \\
\text { CBX4, DEPDC6, GATA6, HEY2, } \\
\text { HSP90B1, IL1A, INSL3, ITSN1, } \\
\text { NOCTCH, PAWR, PDCD6IP, } \\
\text { PHLDA1, PRKCD, RAD21, } \\
\text { RNF34, RPS6KA3, SIRT1, } \\
\text { TGFBR1, TNF, TNFAIP1, } \\
\text { UBE2B, TRIM2, USP47, CCNG1 }\end{array}$ & $\begin{array}{l}\text { ATM, BIRC6, CARD11, CDON, } \\
\text { GATA6, HEY2, IGF2BP2, } \\
\text { IL1A, ING5, INSL3, IRS2, } \\
\text { LRRC32, MCC, NR6A1, PAWR, } \\
\text { PDAP1, PLAU, PRDM4, } \\
\text { PROX1, RBBP7, SERPINE1, } \\
\text { SPRK2, TNF, S1PR1, } \\
\text { KRAS, TNS3 }\end{array}$ & - \\
\hline hsa-miR-513a-5p & $\begin{array}{l}\text { CDK6, CHEK2, } \\
\text { GRB2, HMGCR, } \\
\text { SERP1 }\end{array}$ & $\begin{array}{l}\text { BNIP3L, CHEK2, ECE1, EYA1, } \\
\text { MAPK7, NOD2, PHLDB3, } \\
\text { PPARGC1A, RAG1, XIAP, } \\
\text { TRIM2, USP47 }\end{array}$ & $\begin{array}{l}\text { ASH2L, ATF3, CDK6, DDX11, } \\
\text { EHF, EPS8, EYA1, MAGI2, } \\
\text { NOD2, PCAF, PDS5B, } \\
\text { PURA, SMAD2, TBX19, } \\
\text { VSX2, S1PR1, KRAS }\end{array}$ & - \\
\hline hsa-miR-455-5p & LRP2, SOCS3 & $\begin{array}{l}\text { ETS1, FZD5, GABRB2, KPNA1, } \\
\text { SOCS3, TJP1, GP1 }\end{array}$ & $\begin{array}{l}\text { CDC2L5, FZD5, IRF2, KDR, } \\
\text { LRP2, NCK2, PTPRJ, } \\
\text { PDGFRA, SOX11 }\end{array}$ & - \\
\hline hsa-miR-574-3p & - & CUL2, RXRA & CUL2, RXRA & - \\
\hline hsa-miR-654-5p & $\mathrm{BBC} 3, \mathrm{DBH}$ & ARAF, BBC3, WNT11, KPNB1 & $\begin{array}{l}\text { DBH, EFNB1, ELLN, TIMP2, } \\
\text { WNT11, IRS1, MTSS1 }\end{array}$ & - \\
\hline hsa-miR-758 & JUN & BCL11B, BMP7, RABEP1 & $\begin{array}{l}\text { BCL11B, BMP7, IGF1, } \\
\text { JUN, STAT5B }\end{array}$ & BCL11B \\
\hline hsa-miR-765 & LMNA, TIMP3 & EGLN2, LMNA, OSM & $\begin{array}{l}\text { CDK2, CSF1R, OSM, } \\
\text { TXLNA, GPC3 }\end{array}$ & - \\
\hline hsa-miR-1271 & $\begin{array}{l}\text { CASP2, DDIT3, } \\
\text { EDNRA, MAP2K1 }\end{array}$ & $\begin{array}{l}\text { ALK, AHR, DDIT3, DOCK1, } \\
\text { EDNRA, EPHA3, FOXO1, } \\
\text { FOXQ1, MBD4, OGT, PLAGL1, } \\
\text { PRKCE, PROK2, PSME4, } \\
\text { RALB, STK17A, TNFSF13B, } \\
\text { TRIB3, TXNDC1, CCNG1, } \\
\text { SORT1, KPNB1 }\end{array}$ & $\begin{array}{l}\text { AHR, CD164, DIXDC1, EDNRA, } \\
\text { FRAP1, FRS2, FYN, HOOK3, } \\
\text { LAMC1, LIPG, MAB21L2, } \\
\text { MAP2K1, MED1, MYO16, } \\
\text { NEUROD4, PGGT1B, TACC1, } \\
\text { TNFSF13B, TXNDC1, TNS3, } \\
\text { HBEGF, KRAS, IRS1, } \\
\text { MTSS1, GPC3 }\end{array}$ & - \\
\hline
\end{tabular}

asterisk following the name indicates non-functional miRNA or passenger strand that is released from the miRNA duplex (26). Recent studies suggest that miRNA* may offer potential opportunities for contributing to the regulation network (27).
As shown in Fig. 2B, 19 miRNAs were upregulated and 21 miRNAs were downregulated under the experimental conditions. Although the majority of miRNAs did not show significant changes in expression, treatment with TECA did 


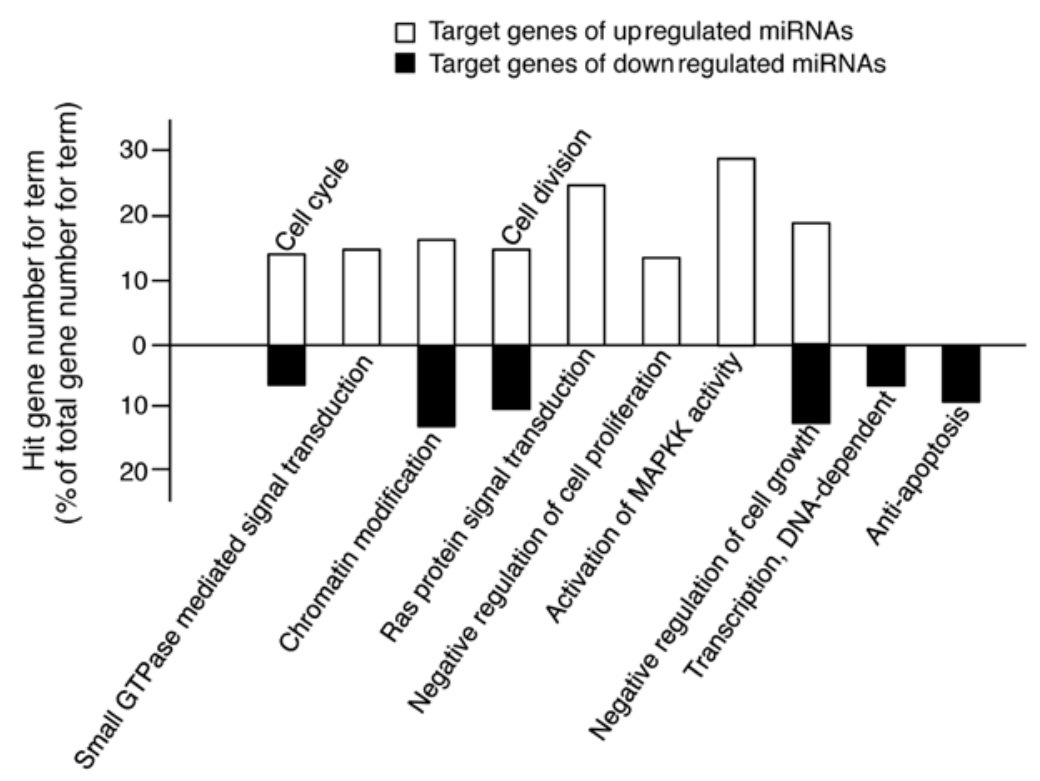

Figure 4. Identification of sub-biological processes/functions of the miRNA target genes. The target genes of the TECA-specific differentially expressed miRNAs were predicted by Gene Set Enrichment Analysis using the starBase tool. The values on the y-axis of the graph represent percentage of gene hits for the GO term compared to the total genes for the term.

affect certain miRNA expression levels in NHDFs. These differentially expressed miRNAs may be involved in specific mechanisms of TECA-mediated cellular responses during the inhibition of UVB-induced cell damage in NHDFs.

Bioinformatic analysis of TECA-specific miRNAs and their putative target genes in UVB-induced damage in NHDF cells. miRNA expression profiling suggested a protective role of TECA against UVB-induced damage that may be dependent on the regulation of TECA-specific miRNA expression. These results further highlight the significance of the altered miRNA expression in light of the photoprotective property of TECA in UVB-induced damage of NHDFs. Since the cellular functions of miRNAs are mediated by controlling their target gene expression (28), we analyzed the cellular meaning of the TECA-dependent miRNA expression changes by sorting them according to three independent criteria (Fig. 3): i) the putative target genes of the differentially expressed miRNAs; ii) the cellular functions of the target genes; and iii) the target genes involved in TECA-mediated protective properties. First, using the miRBase Target Database tool, Microcosm, we identified approximately 2,758 potential targets for all miRNA, excluding human viral miRNAs. A total of 1,479 genes were identified as potential target genes for the upregulated miRNAs and 1,279 genes were identified as potential target genes for the downregulated miRNAs. Next, we identified the potential target genes involved in TECA-mediated protective properties against UVB damage, such as aging, apoptosis, cell proliferation and skin development. Using a GO web-based tool, AmiGO, we arranged the gene information in four classes: a total of 388 genes in aging, 3,824 genes in apoptosis, 3,148 genes in cell proliferation and 399 genes in skin development were identified (data not shown). We then compared these genes with the putative target genes $(1,479$ genes corresponding to upregulated miRNAs and 1,279 genes corresponding to downregulated miRNAs), and the overlap- ping genes in the two groups are listed in Tables II and III. Some of the miRNAs were potentially targeted by more than one miRNA, since a single miRNA may target a number of mRNAs, and, conversely, a single mRNA target may be modulated by several miRNAs (29).

The GO terms in Tables II and III cover a relatively wide range of cellular processes. For example, the GO term of apoptosis encompasses all the genes involved in apoptosis-promoting and apoptosis-inhibiting processes. Therefore, for a more accurate analysis, we rearranged the results shown in Tables II and III into a subset of GO terms, such as positive or negative regulation of the cell cycle, cell division, cell proliferation, cell growth and apoptosis, GTPase-, Ras-, MAPKK-mediated signal transduction and DNA-dependent transcription. As shown in Fig. 4, the target genes of the upregulated miRNAs are involved in promoting processes of cell proliferation; however, the target genes of the downregulated miRNAs are involved in inhibiting processes of apoptosis. Therefore, these findings suggest that TECAmediated protective effects against UVB-induced damage in NHDFs is related to the changes in expression of specific miRNAs involved in cell proliferation and apoptosis.

\section{Discussion}

The present study demonstrated that TECA exhibits a protective effect against UVB-mediated damage in NHDF cells via regulation of miRNA expression. The cytotoxicity and viability assay revealed that a low dose of TECA (25 and $50 \mu \mathrm{g} / \mathrm{ml}$ ) is not toxic to NHDF cells, and UVB-mediated loss of cell viability is recovered by stimulation with low doses of TECA. Also, TECA stimulation of NHDF cells changes their miRNA expression profiles, and the differentially expressed miRNAs may have potential anti-apoptotic properties, as revealed by a bioinformatic analysis of their putative target genes and GO analysis of the target genes. Therefore, TECA- 
mediated changes in miRNA expression may regulate the anti-proliferative effect of UVB irradiation on NHDF cells.

The bioinformatic analysis shown in Fig. 4 may represent the paradoxical roles of TECA in NHDF cell proliferation, since some of the target genes of the upregulated miRNAs were functionally associated with positive regulation of the cell cycle and cell division and with negative regulation of cell growth, thus suggesting that the TECA-mediated upregulation of miRNAs can inhibit cell proliferation. However, these results may be due to the residual cytotoxicity of UVB irradiation in the system used. The fact that treatment with $50 \mu \mathrm{g} / \mathrm{ml}$ TECA did not completely restore the UVB-induced loss of cell viability to the normal status indicates that the antiproliferative effect of UVB remained, although at a low level, in the experiments shown in Fig. 1B. Of note, the target genes of the miRNAs that were downregulated by TECA were functionally related to anti-apoptosis, negative regulation of cell growth, cell cycle and cell division. These results demonstrate that the downregulated miRNAs can functionally induce pathways of anti-apoptosis and cell proliferation.

Additionally, the target genes of the miRNAs upregulated by TECA were shown to be involved in small GTPasemediated signal transduction and Ras protein signal transduction. These results indicate that the TECA-mediated anti-apoptotic effect against UVB-mediated NHDF damage can be mediated by inhibiting the small GTPase- and Ras-mediated signaling pathways via upregulation of miRNAs that target the genes involved in the above mechanisms. Rac1 is a small Rho GTPase, which is a key transducer of proliferation and apoptosis in various cells, including NHDFs (30-32). Racl has primarily been found to induce NHDF proliferation via phosphorylation of the oncogene c-myc (32). However, the pro-apoptotic roles of Racl have been reported in previous studies. Rac1 induces apoptosis via JNK in epithelial cells (33). Also, Rac1 stimulates apoptosis through the activation of trivalent chromium in human dermal fibroblasts (34). Furthermore, Rac1 is necessary for the apoptotic process induced by UV irradiation in Rat-2 fibroblasts, suggesting a stimulatory role of Racl in apoptosis caused by perturbation of homeostasis (35). Although Ras proteins are known as oncogenes, their pro-apoptotic function has also been reported. UV irradiation induces apoptosis via the activation of Ha-ras and via increasing the phosphorylation of Raf-1 and subsequently activating c-Jun and other AP-1 proteins (36). The R-Ras protein promotes apoptosis that is caused by growth factor deprivation in Rat-1 fibroblasts. Furthermore, in response to stress, the GTP-bound Ras activates MEKKSEK-SARK-c-JUN and induces apoptosis (37-39). Therefore, there is a strong possibility that the protective effect of TECA treatment in UVB-irradiated NHDFs can be induced by upregulation of specific miRNAs that inhibit the signal transduction mediated by small GTPases and Ras.

We also showed that the majority of the target genes of the miRNAs upregulated by TECA were involved in the activation of MAPKK activity. MAPKK is a kinase that phosphorylates a MAPK, such as p38, JNK and ERK1/2. UV irradiation of skin cells including keratinocytes, melanocytes and dermal fibroblasts can regulate cell fate via the activation of MAPKmediated signaling pathways. UV-activated p38 MAPK and JNK in skin cells have been shown to be involved in both cell survival and cell death pathways (40-43). However, the ERK1/2 pathway has been implicated in generating anti-apoptotic signals in skin cells (44). Also, UV irradiation did not increase p38 and JNK protein synthesis in the cells, but rather increased the level of phosphorylated p38 activity $(45,46)$. These results indicate that UV irradiation causes phosphorylation-mediated activation of p38 MAPK, JNK and ERK1/2 in skin cells; however, its effects on cells can be observed in both apoptosis and cell survival. Therefore, the reason that the target genes of upregulated miRNAs are highly involved in the activation of MAPKK activity is the possibility that the UVB-protective properties of TECA can be mediated through the regulation of biphasic MAPK responses.

In conclusion, we determined for the first time that TECA treatment of UVB-exposed NHDF cells causes a photoprotective effect via a change in miRNA expression. The cellular mechanisms underlying the photoprotective effect of TECA against UV irradiation remain unknown; however, our study provides substantial evidence of the role of TECA as a chemoprotective agent against UVB-mediated damage in human dermal fibroblasts. Although further studies must be performed to verify the predicted miRNA targets identified in this study, our results suggest that characterization of TECAspecific miRNA changes may provide a useful approach to understanding cellular responses to TECA in UVB-induced NHDF damage.

\section{Acknowledgements}

We thank all the members of our research group for their support and advice during this study. This study was supported by the Ministry of Education, Science and Technology (grant 20110028646 to S.A.) of the Republic of Korea.

\section{References}

1. Coldren CD, Hashim P, Ali JM, Oh SK, Sinskey AJ and Rha C: Gene expression changes in the human fibroblast induced by Centella asiatica triterpenoids. Planta Med 69: 725-732, 2003.

2. Brinkhaus B, Lindner M, Schuppan D and Hahn EG: Chemical, pharmacological and clinical profile of the East Asian medical plant Centella asiatica. Phytomedicine 7: 427-448, 2000.

3. James JT and Dubery IA: Pentacyclic triterpenoids from the medicinal herb, Centella asiatica (L.) Urban. Molecules 14: 3922-3941, 2009.

4. Jayashree G, Kurup Muraleedhara G, Sudarslal S and Jacob VB: Anti-oxidant activity of Centella asiatica on lymphoma-bearing mice. Fitoterapia 74: 431-434, 2003.

5. Babu TD, Kuttan G and Padikkala J: Cytotoxic and anti-tumour properties of certain taxa of Umbelliferae with special reference to Centella asiatica (L.) Urban. J Ethnopharmacol 48: 53-57, 1995.

6. Maquart FX, Chastang F, Simeon A, Birembaut P, Gillery P and Wegrowski Y: Triterpenes from Centella asiatica stimulate extracellular matrix accumulation in rat experimental wounds. Eur J Dermatol 9: 289-296, 1999.

7. Bonte F, Dumas M, Chaudagne C and Meybeck A: Influence of asiatic acid, madecassic acid, and asiaticoside on human collagen I synthesis. Planta Med 60: 133-135, 1994.

8. Cesarone MR, Belcaro G, De Sanctis MT, et al: Effects of the total triterpenic fraction of Centella asiatica in venous hypertensive microangiopathy: a prospective, placebo-controlled, randomized trial. Angiology 52 (Suppl 2): 15-18, 2001.

9. Incandela L, Cesarone MR, Cacchio M, et al: Total triterpenic fraction of Centella asiatica in chronic venous insufficiency and in high-perfusion microangiopathy. Angiology 52 (Suppl 2): 9-13, 2001. 
10. Bonte F, Dumas M, Chaudagne $\mathrm{C}$ and Meybeck A: Comparative activity of asiaticoside and madecassoside on type I and III collagen synthesis by cultured human fibroblasts. Ann Pharm Fr 53: 38-42, 1995 (In French).

11. Tenni R, Zanaboni G, De Agostini MP, Rossi A, Bendotti C and Cetta G: Effect of the triterpenoid fraction of Centella asiatica on macromolecules of the connective matrix in human skin fibroblast cultures. Ital J Biochem 37: 69-77, 1988.

12. Maquart FX, Bellon G, Gillery P, Wegrowski Y and Borel JP: Stimulation of collagen synthesis in fibroblast cultures by a triterpene extracted from Centella asiatica. Connect Tissue Res 24: 107-120, 1990.

13. Ott T, Fritz E, Polle A and Schutzendubel A: Characterisation of antioxidative systems in the ectomycorrhiza-building basidiomycete Paxillus involutus (Bartsch) Fr. and its reaction to cadmium. FEMS Microbiol Ecol 42: 359-366, 2002.

14. Mustafa RA, Abdul Hamid A, Mohamed S and Bakar FA: Total phenolic compounds, flavonoids, and radical scavenging activity of 21 selected tropical plants. J Food Sci 75: C28-C35, 2010.

15. Kim YJ, Cha HJ, Nam KH, Yoon Y, Lee H and An S: Centella asiatica extracts modulate hydrogen peroxide-induced senescence in human dermal fibroblasts. Exp Dermatol 20: 998-1003, 2011.

16. Clydesdale GJ, Dandie GW and Muller HK: Ultraviolet light induced injury: immunological and inflammatory effects. Immunol Cell Biol 79: 547-568, 2001.

17. Hennessy A, Oh C, Rees J and Diffey B: The photoadaptive response to ultraviolet exposure in human skin using ultraviolet spectrophotometry. Photodermatol Photoimmunol Photomed 21: 229-233, 2005.

18. Matsumura Y and Ananthaswamy HN: Toxic effects of ultraviolet radiation on the skin. Toxicol Appl Pharmacol 195: 298-308, 2004

19. Muthusamy V and Piva TJ: The UV response of the skin: a review of the MAPK, NFkappaB and TNFalpha signal transduction pathways. Arch Dermatol Res 302: 5-17, 2010.

20. Hashim P, Sidek H, Helan MH, Sabery A, Palanisamy UD and Ilham M: Triterpene composition and bioactivities of Centella asiatica. Molecules 16: 1310-1322, 2011.

21. Yang JH, Li JH, Shao P, Zhou H, Chen YQ and Qu LH: starBase: a database for exploring microRNA-mRNA interaction maps from Argonaute CLIP-Seq and Degradome-Seq data. Nucleic Acids Res 39: D202-D209, 2011.

22. Ambros V and Lee RC: Identification of microRNAs and other tiny noncoding RNAs by cDNA cloning. Methods Mol Biol 265 131-158, 2004

23. Cheng AM, Byrom MW, Shelton J and Ford LP: Antisense inhibition of human miRNAs and indications for an involvement of miRNA in cell growth and apoptosis. Nucleic Acids Res 33: 1290-1297, 2005.

24. Chen JF, Mandel EM, Thomson JM, et al: The role of microRNA-1 and microRNA-133 in skeletal muscle proliferation and differentiation. Nat Genet 38: 228-233, 2006

25. Cho WJ, Shin JM, Kim JS, et al: miR-372 regulates cell cycle and apoptosis of ags human gastric cancer cell line through direct regulation of LATS2. Mol Cells 28: 521-527, 2009.

26. O'Toole AS, Miller S, Haines N, Zink MC and Serra MJ: Comprehensive thermodynamic analysis of 3' double-nucleotide overhangs neighboring Watson-Crick terminal base pairs Nucleic Acids Res 34: 3338-3344, 2006.

27. Guo L and Lu Z: The fate of miRNA* strand through evolutionary analysis: implication for degradation as merely carrier strand or potential regulatory molecule? PLoS One 5: e11387, 2010.

28. Pillai RS, Bhattacharyya SN and Filipowicz W: Repression of protein synthesis by miRNAs: how many mechanisms? Trends Cell Biol 17: 118-126, 2007.
29. John B, Enright AJ, Aravin A, Tuschl T, Sander C and Marks DS: Human MicroRNA targets. PLoS Biol 2: e363, 2004.

30. Jaffe AB and Hall A: Rho GTPases: biochemistry and biology. Annu Rev Cell Dev Biol 21: 247-269, 2005.

31. Wang $L$ and Zheng Y: Cell type-specific functions of Rho GTPases revealed by gene targeting in mice. Trends Cell Biol 17 58-64, 2007.

32. Nikolova E, Mitev V, Zhelev N, Deroanne CF and Poumay Y: The small Rho GTPase Racl controls normal human dermal fibroblasts proliferation with phosphorylation of the oncoprotein c-myc. Biochem Biophys Res Commun 359: 834-839, 2007.

33. Jin S, Ray RM and Johnson LR: Rac1 mediates intestinal epithelial cell apoptosis via JNK. Am J Physiol Gastrointest Liver Physiol 291: G1137-G1147, 2006.

34. Rudolf $\mathrm{E}$ and Cervinka M: Trivalent chromium activates Rac-1 and Src and induces switch in the cell death mode in human dermal fibroblasts. Toxicol Lett 188: 236-242, 2009.

35. Eom YW, Yoo MH, Woo CH, et al: Implication of the small GTPase Rac1 in the apoptosis induced by UV in Rat-2 fibroblasts. Biochem Biophys Res Commun 285: 825-829, 2001.

36. Devary Y, Gottlieb RA, Smeal T and Karin M: The mammalian ultraviolet response is triggered by activation of Src tyrosine kinases. Cell 71: 1081-1091, 1992.

37. Ramirez MT, Sah VP, Zhao XL, Hunter JJ, Chien KR and Brown JH: The MEKK-JNK pathway is stimulated by alpha1adrenergic receptor and ras activation and is associated with in vitro and in vivo cardiac hypertrophy. J Biol Chem 272: 14057-14061, 1997.

38. Sanchez I, Hughes RT, Mayer BJ, et al: Role of SAPK/ERK kinase-1 in the stress-activated pathway regulating transcription factor c-Jun. Nature 372: 794-798, 1994

39. Yan M, Dai T, Deak JC, et al: Activation of stress-activated protein kinase by MEKK1 phosphorylation of its activator SEK1. Nature 372: 798-800, 1994

40. Chouinard N, Valerie K, Rouabhia M and Huot J: UVB-mediated activation of p38 mitogen-activated protein kinase enhances resistance of normal human keratinocytes to apoptosis by stabilizing cytoplasmic p53. Biochem J 365: 133-145, 2002.

41. Hildesheim J, Awwad RT and Fornace AJ Jr: p38 Mitogenactivated protein kinase inhibitor protects the epidermis against the acute damaging effects of ultraviolet irradiation by blocking apoptosis and inflammatory responses. J Invest Dermatol 122: 497-502, 2004.

42. Chen YR, Wang X, Templeton D, Davis RJ and Tan TH: The role of c-Jun N-terminal kinase (JNK) in apoptosis induced by ultraviolet $\mathrm{C}$ and gamma radiation. Duration of JNK activation may determine cell death and proliferation. J Biol Chem 271: 31929-31936, 1996.

43. Wisdom R, Johnson RS and Moore C: c-Jun regulates cell cycle progression and apoptosis by distinct mechanisms. EMBO J 18: 188-197, 1999.

44. He YY, Huang JL and Chignell CF: Delayed and sustained activation of extracellular signal-regulated kinase in human keratinocytes by UVA: implications in carcinogenesis. J Biol Chem 279: 53867-53874, 2004

45. Cho JW, Park K, Kweon GR, et al: Curcumin inhibits the expression of COX-2 in UVB-irradiated human keratinocytes (HaCaT) by inhibiting activation of AP-1: p38 MAP kinase and JNK as potential upstream targets. Exp Mol Med 37: 186-192, 2005.

46. Kim AL, Labasi JM, Zhu Y, et al: Role of p38 MAPK in UVB-induced inflammatory responses in the skin of SKH-1 hairless mice. J Invest Dermatol 124: 1318-1325, 2005. 